\title{
ELUCIDAR LA CONTRIBUCIÓN DE LAS PROTEÍNAS EN LAS LÁGRIMAS. UN RETO PARA LOS INVESTIGADORES
}

\author{
ELUCIDATE THE CONTRIBUTION OF PROTEINS TO TEARS. A \\ CHALLENGE FOR RESEARCHERS
}

\begin{abstract}
MILLAR TJ ${ }^{1}$
Bajo la idea predominante y casi desdeñosa de que el papel de las proteínas en las lágrimas es antimicrobiano e inmunológico, ha existido un trasfondo persistente de sus incondicionales que investigan la contribución física de las proteínas a la lágrima. Es aquí donde entramos en el reino de la tensión superficial y la viscoelasticidad y de las abundantes publicaciones de Frank Holly, Anthony Bron y John Tiffany. Una tensión superficial baja y una viscosidad no-newtoniana alta son esenciales para la estabilidad de la película lagrimal y la adecuada lubricación de la superficie ocular y parece que las proteínas son imprescindibles para estas propiedades.

De los muchos cientos de proteínas que actualmente se sabe que se presentan en la lágrima humana (1), la lipocalina lagrimal $(\sim 18 \mathrm{kD})$ ha atraído especial atención por su posible papel sobre la tensión superficial y la viscoelasticidad. Esto se debe a su relativa abundancia (15-33\% de la proteína total de la lágrima), su relativamente pobre actividad antimicrobiana y su capacidad de unir lípidos y por consiguiente de interactuar con la capa lipídica en la superficie externa de la película lagrimal. Comparando los cambios en la tensión superficial de las lágrimas deplecionadas de lípidos y de las mezclas de varias proteínas lagrimales, Nagyova y Tiffany dedujeron que la lipocalina lagrimal interaccionaba con los lípidos de la superficie para disminuir la tensión superficial (2). Esta idea de que las proteínas interactúan con la capa lipídica ha sido llevada un paso más lejos por nuestro grupo. Actualmente creemos que las proteínas son una parte integral de la interfase aire-líquido de la película lagrimal y que no se limitan simplemente a interactuar con los

lípidos subyacentes. La evidencia ha procedido en parte de la comparación de los cambios dinámicos en la tensión superficial de las grasas meibomianas, fosfolípidos, mucina ocular, lágrima completa y proteínas lagrimales en una artesa de Langmuir. De ahí se ha hecho evidente que las proteínas, no sólo los lípidos meibomianos por sí solos, son necesarias para disminuir la tensión superficial hasta la encontrada en la lágrima completa. Aún más, estas proteínas incluyen las principales proteínas de la lágrima, tales como la lisozima y las mucinas $(3,4)$. Curiosamente, la lipocalina está dando resultados desconcertantes (no publicados) que indican que la apolipocalina es capaz de penetrar una capa lipídica, pero que la hololipocalina (la lipocalina cargada con lípidos) parece quedar atrapada en la capa acuosa. Por contraste, otras proteínas lagrimales se despliegan en la superficie y quedan atrapadas en la capa lipídica. Mediante un marcado de las proteínas y los lípidos con unas etiquetas fluorescentes, hemos conseguido demostrar que la presencia de proteínas provoca que la capa superficial se parezca más a un gel que a la capa móvil que se forma cuando sólo los lípidos componen la capa superficial. Esto es equiparable a los hallazgos clínicos, donde el patrón superficial de la película lagrimal es estable después de múltiples parpadeos.

En términos de viscosidad lagrimal, un reciente trabajo, muy interesante pero desconcertante, de Gouveia y Tiffany (5), indica que las soluciones puras de lisozima, lactoferrina, IgA o lágrimas sin lípidos se comportan como fluidos newtonianos, es decir, a medida que un objeto es movido más rápido a través de un fluido (velocidad de avance) la
\end{abstract}

\footnotetext{
1 Profesor asociado. Escuela de Ciencias Naturales. Universidad de Sydney Oeste.

E-mail: T.Millar@uws.edu.au
} 
resistencia que provoca (viscosidad) no varía. Las lágrimas completas (con lípidos) se comportan de modo bastante diferente: su viscosidad cae rápidamente al incrementar la velocidad de avance. Esto se conoce como «aclaramiento con el avance» o comportamiento no-newtoniano y se cree que es importante para reducir la resistencia en la superficie ocular con el parpadeo. En contraste con las soluciones proteicas puras, las mezclas de las combinaciones de proteínas arriba mencionadas o de apolipocalina sola muestran un «aclaramiento con el avance» similar al de las lágrimas normales. La hololipocalina (con lípidos) muestra un comportamiento newtoniano. A estas alturas, no hay otras explicaciones para estos desconcertantes fenómenos más que el hecho de que se tratan de mezclas de proteínas con proteínas y de proteínas distintas a la lipocalina con lípidos las que dan a las lágrimas sus propiedades no-newtonianas. En este punto es importante el concepto de la interacción proteica en las lágrimas más que el papel de las proteínas individuales. Esta interacción de las proteínas no ha pasado desapercibida por el equipo de Ben Glasgow, que ha descrito que la lipocalina interacciona tanto con la lactoferrina como con la lisozima, pero no con la albúmina y consiguientemente ha sugerido que existe una «independencia funcional de estas proteínas en la formación de la película lagrimal». Es importante el hecho de que esta interacción es iónica y se ve trastocada por altas concentraciones de sales. Sólo de forma especulativa, esto podría ayudar a explicar la habitual asociación de osmolaridad alta y ojo seco: altas concentraciones de sales interfieren en las interacciones proteínaproteína, lo que conlleva una alteración en la viscoelasticidad y en las propiedades surfactantes de las proteínas en las lágrimas que a su vez conduce a una rápida rotura lagrimal.
Estos estudios sobre la contribución que las proteínas tienen en la naturaleza física de las lágrimas conllevan muchas posibilidades fascinantes. ¿Pueden las proteínas inflamatorias alterar el funcionamiento físico de las proteínas habituales de las lágrimas? ¿Cuáles son las contribuciones de algunas de las cuantitativamente escasas proteínas a las propiedades físicas de las lágrimas, o de forma similar, de las proteínas que son relativamente abundantes, como la lacritina, pero que no tienen hasta ahora un papel definido? Estoy deseando conocer los resultados de los intrépidos jóvenes investigadores que tienen el valor de aceptar el reto de estudiar la película lagrimal como una interacción dinámica de moléculas.

\section{BIBLIOGRAFÍA}

1. Sack RA, Conradi L, Krumbolz D, Beaton A, Satbe S, Morris $C$. Membrane array characterization of 80 chemokines, cytokines and growth factors in open- and closedeye tears: angiogenin and other defense system constituents. Invest Ophthalmol Vis Sci 2005; 46: 1228-1238.

2. Nagyova B, Tiffany JM. Components responsible for the surface tension of human tears. Curr Eye Res 1999; 19: 411.

3. Tragoulias ST, Anderton PJ, Dennis GR, Miano F, Millar TJ. Surface pressure measurements of human tears and individual tear film components indicate that proteins are major contributors to the surface pressure. Cornea 2005; 24: 189-200.

4. Millar TJ, Tragoulias ST, Anderton PJ, Ball MS, Miano F, Dennis GR, et al. The surface activity of purified ocular mucin at the air-liquid interface and interactions with meibomian lipids. Cornea 2006; 25: 91-100.

5. Gouveia SM, Tiffany JM. Human tear viscosity: an interactive role for proteins and lipids. Biochim Biophys Acta 2005; 1753: 155-163.

6. Gasymov OK, Abduragimov RA, Yusifov TN, Glasgow BJ. Interaction of tear lipocalin with lysozyme and lactoferrin. Biochem Biophys Res Commun 1999; 265: 322-325. 